Revista lus et Praxis, Año 22, No 1, 2016, pp. 129 - 164

ISSN 0717 - 2877

Universidad de Talca - Facultad de Ciencias Jurídicas y Sociales

Breve ejercicio de teoría (realista) de la interpretación: veintitrés problemas

interpretativos sobre la regulación del Código Civil chileno sobre la interpretación

Álvaro Núñez Vaquero

Trabajo recibido el 21 de julio y aprobado el 1 de octubre de 2015

\title{
Breve ejercicio de teoría (realista) de la interpretación: veintitrés problemas interpretativos sobre la regulación del Código Civil chileno sobre la interpretación*
}

\author{
A BRIEF EXERCISE ON (REALIST) THEORY OF LEGAL INTERPRETATION: \\ TWENTY-THREE INTERPRETATIVE PROBLEMS ABOUT THE LEGISLATION \\ By ChILEAN Civil CODE ON LEGAL INTERPRETATION
}

ÁlVARo NúÑez Vaquero*

\begin{abstract}
Resumen
El presente trabajo constituye un ejercicio de teoría jurídica realista sobre la interpretación. El objetivo es mostrar que no hay una única interpretación verdadera o correcta de los artículos 19 a 24 del Código Civil chileno. Se comienza, en la primera parte, estableciendo los límites y objetivos del propio trabajo. En la segunda parte, se presentan algunas distinciones conceptuales necesarias para comprender los problemas de interpretación que se derivan de los artículos 19 a 24 del Código Civil chileno. A continuación, se presentan veintitrés problemas relativos a la interpretación de dichos artículos. Se concluye con unas breves consideraciones finales.
\end{abstract}

\section{ABSTRACT}

This work is an exercise in legal realist theory of interpretation. The aim is to show that there is no single true or correct interpretation of Chilean Civil Code 19 to 24 articles. The start, in the first half, establishes the limits and objectives of the work itself. In the second part, some conceptual distinctions, needed to understand the problems of interpretation arising from articles 19-24 of the Chilean Civil Code, are presented. Then, twenty three problems concerning the interpretation of those articles are presented. We conclude with a few short final considerations.

\section{PaLABRAS CLAVE}

Interpretación jurídica, Disposiciones normativas, Normas, Normas interpretativas y ambigüedad

KEYWORDS

Legal interpretation, Normative sentences, Norms, canons of legal interpretation and ambiguity

\footnotetext{
* El presente trabajo se enmarca en el proyecto de investigación Fondecyt del que soy Investigador principal, titulado "Realismo jurídico e interpretación del derecho" ( $\left.\mathrm{N}^{\circ} 11130311\right)$ concedido por el Conicyt chileno. Debo agradecer a los participantes en el Seminario Austral de la Universidad Austral de Chile y en el seminario organizado en la Universidad Diego Portales por sus valiosos comentarios. Además, he recibido observaciones muy pertinentes de Claudio Agüero, Riccardo Guastini, Íñigo de la Maza y Sebastián Ríos a versiones previas de este trabajo, por las que les estoy sumamente agradecido.

** Profesor de Teoría del Derecho, Universidad Austral de Chile. Correo electrónico: alvaro.nunez@ uach.cl.
} 
El objetivo general del presente trabajo es realizar una aportación a la teoría jurídica de la interpretación del derecho desarrollada en Chile. Puede, no obstante, ser leído también como un ejercicio de ciencia jurídica kelseniana, al menos en una de sus versiones ${ }^{1}$ : señalar todos los posibles significados -no que de hecho adopta o ha adoptado, sino- que puede adoptar, conforme a los criterios interpretativos vigentes en una comunidad jurídica ${ }^{2}$ (en este caso, la chilena), un determinado conjunto finito de enunciados normativos ${ }^{3}$. El objetivo específico es señalar algunos problemas que el intérprete del Código Civil Chileno (de ahora en adelante, CCCh) puede encontrar a la hora de atribuir significado a los enunciados normativos de dicho texto que pretenden regular la interpretación jurídica (artículos 19 a 24 del CCCh).

El presente trabajo constituye además un ejercicio de aplicación de las tesis realistas sobre la interpretación del derecho, que vienen sosteniéndose por autores americanos y europeos desde hace varias décadas. Me refiero en concreto a las tesis escépticas sostenidas por autores como: K. Llewellyn, M. Radin o F. Cohen en Estados Unidos; A. Ross, V. Lundstedt y K. Olivecrona, en la cultura jurídica escandinava; R. Guastini, P. Comanducci y P. Chiassoni en el realismo jurídico genovés; M. Troper, P. Brunet y E. Millard en el realismo jurídico francés, por poner solo algunos de los ejemplos más conocidos. A ellos habría que añadir, por supuesto, las aportaciones de Hans Kelsen, escéptico en teoría de la interpretación jurídica ${ }^{4}$.

\section{Algunas aclaraciones previas}

Antes de comenzar a analizar la regulación del CCCh sobre interpretación jurídica, es necesario realizar algunas aclaraciones previas respecto del objetivo de este trabajo.

1.1. La primera se refiere al objetivo del trabajo, que es exclusivamente teórico. No se pretende en este trabajo ofrecer una respuesta acerca de cuál

\footnotetext{
${ }^{1}$ Me permito remitir a NúÑez (2014a).

2 Por "comunidad jurídica" entiendo el conjunto de personas involucradas en el estudio, interpretación y/o aplicación de un determinado ordenamiento jurídico (lo que una parte de la literatura llama cultura jurídica interna). Considero que un criterio interpretativo está vigente toda vez que existe un acuerdo amplio -lo que no deja de ser una cuestión de grado- entre los miembros de la comunidad jurídica que considera dicho criterio como un instrumento legítimo (aceptado como tal) para dotar de significado a los enunciados normativos. Mi noción de vigencia es puramente empírica en el sentido de que son legítimos todos aquellos instrumentos de interpretación que son considerados como tales por la mayoría de la comunidad jurídica.

${ }^{3}$ Un ejercicio similar respecto a la regulación del Código Civil italino se puede encontrar en GuASTINı (2011), pp. 310 y ss.

${ }^{4}$ KeLSEN (2011).
} 
sería la auténtica, verdadera o correcta interpretación de los artículos 19 a 24 del CCCh. Tampoco se pretende intentar resolver ningún problema sobre la interpretación del resto de artículos del CCCh, de la ley en general, o de todo el ordenamiento jurídico chileno. Ni, por último, tampoco se intentará establecer ninguna propuesta práctica acerca de qué deberían hacer jueces, abogados, dogmáticos ni cualquier otro operador jurídico a la hora de interpretar el derecho.

No obstante lo anterior, algunas de las tesis que se presentan aquí pueden ser de alguna relevancia para quienes critican el supuesto activismo de los jueces chilenos. Aunque, como ya se ha dicho, el objetivo de este trabajo no es orientar a ningún operador jurídico sobre cómo debe interpretar el derecho, las tesis que aquí se presentan podrían ser relevantes como argumentos para analizar el supuesto activismo de los jueces chilenos. Ello debido a que si la interpretación fuese siempre, o en la mayoría de ocasiones, una actividad con amplios márgenes de discrecionalidad, entonces la acusación de activismo hacia un grupo de jueces, al menos en este sentido, debería ser descartada, puesto que los jueces no podrían no elegir entre diferentes interpretaciones en disputa. De este modo, si "activismo judicial" quiere decir que los jueces eligen entre interpretaciones alternativas en conflicto con base en sus preferencias, entonces los jueces no pueden no ser activistas en este sentido, por lo que la acusación carecería de sentido.

1.2. La segunda aclaración tiene también carácter negativo, en el sentido de que indica lo que no se pretende hacer en este trabajo. No es de ningún modo objetivo o finalidad de este trabajo dar cuenta del debate que se ha producido desde la promulgación del CCCh acerca de cuál es o debería ser su interpretación correcta, Ilevada sobre todo por civilistas ${ }^{5}$, pero también desde una perspectiva más teórica e histórica ${ }^{6}$.

Mis tesis, en este sentido, no pretenden discutir con ninguna concreta doctrina de la interpretación sino, como se verá, con todas ellas. Ello debido a que las críticas que dirigiré a las doctrinas de la interpretación -aquellas tesis que consideran que existe en los artículos 19 a 24 del CCCh una jerarquía ordenada (no vaga ni antinómica) de los criterios de interpretación o que uno de ellos tiene una preferencia absoluta por encima de todos los demás (conformando un sistema normativo ordenado)- son aplicables a todas ellas. En este sentido sostendré que, para ser correctas, dichas doctrinas deberían probar que existen criterios de interpretación últimos de origen jurídico que orienten la elección sobre qué significado atribuir a los artículos 19 a 24 del CCCh. Defenderé, en

${ }_{5}^{5}$ Para un análisis de las diversas posiciones sobre la interpretación de la ley, véase Rodrícuez (1990).

${ }^{6}$ Me refiero aquí a los trabajos de Guzmán (1992), BAsCuñán (2013). 
este sentido, que tales doctrinas o bien son tesis normativas que no nos dicen nada (o poco) sobre cómo prescribe el derecho que sea él mismo interpretado (sino como debería ser desde un punto de vista político externo al propio derecho), o bien son tesis descriptivas que intentan mostrar lo que diría el derecho sobre su propia interpretación, pero son tesis falsas.

No obstante, con el fin de orientar en mayor medida al lector no familiarizado con el debate sobre la interpretación de los artículos 19 a 24 del CCCh, introduciré algunas referencias a los protagonistas y textos más importantes de dicho debate.

1.3. La tercera aclaración se refiere a lo que sí quiero hacer en este trabajo: señalar problemas de interpretación de los enunciados que regulan la interpretación de la ley del CCCh que, en mi opinión, carecen de una solución única en el ordenamiento jurídico chileno. A decir verdad, este tipo de problemas carecen de solución también en otros ordenamientos como el español, el italiano o el colombiano. No se trata pues de que el CCCh sea especialmente defectuoso, sino de un problema propio de la regulación positiva de la interpretación jurídica ${ }^{7}$.

\section{Precisiones conceptuales}

Una vez aclarado el objetivo de este trabajo, es conveniente introducir algunas tesis y distinciones fundamentales para entender desde qué marco teórico voy a analizar las disposiciones comprendidas entre los artículos 19 y 24 del CCCh.

2.1. La primera distinción importante es la que nos permite diferenciar entre enunciados normativos, disposiciones normativas o textos legales, por un lado, y el significado de dichos textos o normas ${ }^{8}$, por el otro. Como han demostrado otros autores ${ }^{9}$, esta distinción es la que permite dar cuenta de la mejor manera posible de en qué consiste la interpretación jurídica: en la atribución de significado a los textos normativos.

La razón según la cual este concepto de interpretación (que presupone la distinción entre enunciados normativos y normas) es el que mejor permite entender qué es la interpretación es que este concepto de interpretación como atribución de significado tiene preferencia lógica frente a aquel que define la interpretación como aclaración de significados oscuros. Ello se debe a que la aclaración de un significado es una actividad posterior y que presupone la

\footnotetext{
7 TARello (2013), cap. V.

${ }^{8}$ No sostengo que las normas sean el significado de los enunciados normativos, pues así resultaría imposible dar cuenta de las normas implícitas o de las consuetudinarias. Sostengo, por el contrario, que las normas son contenidos proposicionales en función prescriptiva, siendo los significados atribuidos a los enunciados normativos solo un tipo particular de la clase general de las normas.
}

9 Dicıotтı (1999), pp. 58-59; Pozzolo (2011). 
atribución de significado a un enunciado. Para determinar si un significado es o no claro, por tanto, es preciso llevar a cabo previamente un acto de atribución de significado, siendo la clarificación del significado un acto de reatribución de un nuevo significado más preciso al enunciado. En este sentido, este concepto de interpretación permite dar cuenta de la actividad que siempre ha de realizar el intérprete, tanto si el significado es claro como si no lo es.

No obstante, esta distinción entre disposiciones y normas no nos dice todavía nada acerca de la relación que subsistiría entre aquellas. Ni tampoco nos dice nada acerca del carácter de la operación consistente en la atribución de significados a los enunciados normativos: si es una actividad descriptiva, adscriptiva o creativa. Lo que sí nos dice, desde una perspectiva general, es que siempre es necesario atribuir significado a los textos, aunque sea su significado claro; desde una perspectiva más particular, también nos dice que es preciso interpretar los enunciados que conforman los artículos 19 al 24 del $\mathrm{CCCh}^{10}$ para saber cuáles son las normas expresadas por tales disposiciones.

2.2. La segunda tesis que asumo es que las palabras, enunciados o textos no tienen un significado objetivo, natural o propio, sino que el significado de aquellos es dependiente de la comunidad lingüística de referencia o, si se prefiere, de los intérpretes: no existe una relación de causalidad entre palabras y significados ${ }^{11}$. Es decir, el significado de los términos y oraciones es dependiente de las reglas lingüísticas adoptadas en cada comunidad.

Aquello que constituye y caracteriza a cada comunidad lingüística son precisamente las normas usadas para atribuir significados a palabras y textos. Sin embargo, las comunidades lingüísticas están gobernadas por una multiplicidad de reglas. En muchas ocasiones, tal multiplicidad de reglas permite y conduce a atribuir significados diferentes a los mismos textos, y muy frecuentemente no existen reglas claras acerca de escoger entre los diferentes posibles significados.

A partir de la anterior asunción, voy a aceptar que la interpretación de los textos jurídicos no puede ser equiparada a la interpretación del o de los lenguajes naturales. La razón es que si el significado de términos y enunciados es dependiente de las normas empleadas para atribuir significado a textos en cada comunidad lingüística, me parece evidente que los juristas tenemos, además de las reglas del lenguaje natural, una serie de reglas lingüísticas suplementarias que no están presentes en el lenguaje natural ${ }^{12}$. Dicho de manera más directa:

\footnotetext{
${ }^{10}$ Buena prueba de ello es la controversia que su propia interpretación ha generado.

11 El español es una lengua lo suficientemente extendida y diversificada para ofrecer múltiples ejemplos: dependiendo del lugar en el que se profiere, los términos y enunciados pueden significar cosas sumamente diferentes.

12 En este sentido es posible afirmar que el lenguaje jurídico es un lenguaje parcialmente técnico.
} 
la gente no interpreta lo que dicen otras personas a contrario, no recurre a interpretaciones originalistas, ni tampoco a la ratio del enunciado más allá de las intenciones del autor del enunciado. Los juristas disponemos, además de las reglas del lenguaje natural, de otra serie de reglas propias del ámbito jurídico no contempladas en los lenguajes naturales, que llevamos más de dos milenios elaborando y empleando.

Pero, si así están las cosas, entonces ya podemos decir algo interesante sobre en qué consiste el acto lingüístico de atribución de significado. Del mismo modo que definir ${ }^{13}$ o traducir de una lengua a otra ${ }^{14}$, la interpretación consiste en el uso de las normas lingüísticas tanto del lenguaje natural como del lenguaje técnico-jurídico. Es decir, interpretar en el fondo no es nada diferente de utilizar o aplicar normas ${ }^{15}$ : subsumir enunciados particulares (enunciados token) en las reglas del lenguaje (enunciados type).

2.3. La tercera tesis es que las técnicas interpretativas ${ }^{16}$ de la comunidad lingüística jurídica chilena -del mismo modo que las de cualquier otra comunidad jurídica occidental-son sincrónicamente múltiples y diversas, es decir, disponemos en esta comunidad jurídico-lingüística de una serie de técnicas interpretativas que permiten, al menos en relación a algunos enunciados, atribuir diferentes significados a las disposiciones jurídicas. Esto es, tenemos diferentes técnicas interpretativas que permiten derivar, a partir de los mismos enunciados, diferentes normas: aquellas reglas lingüísticas admitidas dentro de la comunidad jurídica como instrumentos válidos para atribuir $-y$ justificar ${ }^{17}$ la atribución de un-significado a los enunciados normativos. Prueba de ello es que buena parte de las controversias jurídicas de derecho que se llevan frente a los tribunales chilenos versan, precisamente, sobre cuál es la correcta interpretación de los textos legales con base en el mismo conjunto de criterios interpretativos.

No sostengo, sin embargo, que la comunidad jurídica chilena sea el reino de la confusión en el que nadie entiende nada. En primer lugar, porque el conjunto de reglas interpretativas vigentes no es ilimitado, y no en todas las ocasiones la pluralidad de normas interpretativas conduce a diferentes soluciones interpretativas o interpretaciones producto. No obstante, considero que la ambigüedad de los textos normativos -la posibilidad de atribuir diferentes significados a,

\footnotetext{
13 Véase Guastini (2004), cap. III.

14 Véase Mazzarese (1998).

15 BULYGIN (1992).

${ }^{16}$ Aquí usaré las expresiones "normas interpretativas", "técnicas interpretativas" y "criterios interpretativos" como expresiones sinónimas. Para una distinción y amplio análisis de ellas, véase CHIASSONI (2011).

17 En este sentido, las técnicas interpretativas funcionan como razones en favor de cada interpretación producto. Véase GuAstinı (2015) § 4 .
} 
o derivar diferentes normas a partir de, un mismo texto- es un fenómeno que se produce con bastante frecuencia (aunque no siempre). Para comprobarlo, resulta suficiente observar las múltiples controversias que se producen sobre la interpretación a atribuir a los textos normativos en la dogmática jurídica chilena y en la práctica de los tribunales.

En segundo lugar, porque existen muchos acuerdos individuales sobre cuál es el significado a atribuir a cada disposición, esto es, es frecuente que exista consenso sobre qué norma expresa cada enunciado normativo del derecho (aunque no sobre todos los enunciados) ${ }^{18}$. Ahora bien, no parece que dichos acuerdos sobre el significado a atribuir a cada disposición puedan ser explicados de manera general como el producto de la adopción y aplicación de una misma doctrina acerca de la interpretación ${ }^{19}$. Es decir, no hay ninguna doctrina sobre la (correcta) interpretación de los artículos 19 a 24 del CCCh que justifique (y explique) el significado atribuido a cada uno de los enunciados normativos del resto del ordenamiento jurídico chileno. Por el contrario, se trata de acuerdos lingüísticos individuales sobre cada disposición a la que, en principio, se le podría atribuir -según las reglas interpretativas vigentes- más de un significado. Dichos acuerdos no parecen responder a una única doctrina de la interpretación, sino más bien a la conveniencia -según los intérpretes- de la interpretación producto en cuestión de cada enunciado.

2.4. La cuarta tesis tiene que ver con el orden de las normas sobre interpretación jurídica. En efecto, parece que las reglas de interpretación no están todas situadas sobre el mismo nivel, ni son todas normas para atribuir directamente significado a textos o enunciados normativos.

Las normas de interpretación para atribuir significado a las disposiciones normativas se sitúan, al menos, en dos planos diferentes:

\footnotetext{
${ }^{18}$ Una cosa es que exista un acuerdo sobre el significado a atribuir a un enunciado, lo que constituye el derecho vigente en el sentido de Ross: el conjunto de normas que los jueces consideran obligatorios y están dispuestos a aplicar llegado el caso. Cosa bien diferente es que quepa atribuir a los enunciados normativos un significado diferente con base en los criterios o reglas de interpretación vigentes. Es preciso señalar que los acuerdos interpretativos son de dos tipos: acuerdos sobre el significado específico a atribuir a un texto normativo; y un acuerdo sobre cuáles son los intrumentos de interpretación legítimos. Véase nota 2.

19 Podría pensarse que existe, en este sentido, un acuerdo convencional sobre cuál es la interpretación correcta de los artículos 19 a 24 del CCCh. Sin embargo, dicha convención parece bien sencillamente ritual, bien poco clara. Podría, en primer lugar, tratarse de una convención meramente ritual en el sentido de que, aunque los juristas concuerdan sobre cuál es la interpretación correcta de tales artículos, a la hora de atribuir significado a otros enunciados ignoran tal convención. Pero también podría, en segundo lugar, ser una convención no clara, en el sentido de que la convención versa sobre normas vagas o cuyas reglas de aplicación (preferencia y exclusión) no son claras. Agradezco a Daniela Accatino y a Claudio Agüero que me han hecho precisar esta tesis.
} 
(a) las normas interpretativas de primer orden, es decir, las normas que sirven para atribuir directamente significado a los textos normativos ${ }^{20}$, esto es, para subsumir enunciados particulares bajo reglas lingüísticas generales;

(b) las normas interpretativas de segundo orden o meta-normas de interpretación, que se configuran como un plano de (meta-) normas que gobiernan el uso de las normas que sirven para dotar de significado a los enunciados normativos (normas interpretativas de primer orden). Es decir, se trata de normas acerca del uso de las normas interpretativas de primer orden.

Dentro de estas meta-normas o normas interpretativas de segundo orden podemos distinguir varios tipos, pero aquí será suficiente con referirse a dos:

(b.1) las normas de exclusión, que son aquellas que califican como prohibido (o inválido) el uso de una norma interpretativa de primer orden;

(b.2) las normas de preferencia, que son aquellas que establecen una relación de prioridad entre diferentes normas interpretativas de primer orden. Dentro de las normas de preferencia, podemos distinguir entre normas de preferencia:

(b.2.1) absoluta, que son aquellas que permiten únicamente excepciones explícitas, y en las que -una vez incorporadas dichas excepciones explícitas al antecedente de la norma- si se constata la condición prevista en el antecedente, se sigue necesariamente la consecuencia normativa ${ }^{21}$;

(b.2.2.) relativa, que son aquellas que permiten -además de las explícitas- excepciones implícitas, o también excepciones explícitas pero que hacen referencia a consideraciones valorativas o vagas (en alguno de las diferentes formas que puede adoptar la vaguedad) ${ }^{22}$.

Lo que voy a sostener es que, además de aquellas de primer orden, también las normas de segundo orden son vagas y antinómicas en sentido pragmático. Es decir, no que califican el mismo comportamiento de maneras incompatibles, sino que califican diferentes comportamientos como debidos (o válidos), siendo imposible cumplir todas ellas en el mismo momento. Dicho de otro modo: tales normas interpretativas obligan (o consideran válido), al mismo tiempo, a recurrir a un ejemplo, atribuir el significado literal y el significado

\footnotetext{
20 Se trata de reglas en las que se subsumen los enunciados lingüísticos individuales (en el sentido de que han sido efectivamente proferidos por alguien) y que, como hemos dicho antes, sirven para atribuir significado a dichos enunciados.

${ }^{21}$ Por ejemplo, una meta-norma de preferencia absoluta sería aquella que exige elegir la interpretación literal salvo en presencia de definiciones legales, pero si no encontramos definición legal alguna, entonces es debido elegir la interpretación literal.

22 Por ejemplo, una meta-norma de preferencia relativa sería aquella que nos dijera que hay que elegir la interpretación literal del enunciado no debe ser ignorada pero que no es obligatorio elegir siempre y necesariamente aquella si concurren otras consideraciones relevantes.
} 
técnico, no siendo posible obviamente satisfacer ambas simultáneamente ${ }^{23}(\mathrm{O}$ establecen varios conjuntos normativos de normas sobre la interpretación entre los que elegir).

Desde luego, sería posible pensar en normas de interpretación de tercer orden (o meta-meta-normas interpretativas), que serían aquellas normas que versarían sobre las normas de interpretación de segundo nivel. Podría, en este sentido, pensarse en una norma de tercer nivel que diera preferencia a una de las meta-normas de segundo orden (o que establecen una serie de reglas y excepciones ordenadas). Cuestión diferente es que dichas normas existan y que además sean jurídicas (o que su aplicación sea indicada por alguna norma jurídica).

2.5. La última tesis que introduciré en este apartado es que los artículos 19 a 24 del CCCh no contemplan ninguna meta-meta-norma o norma interpretativa de tercer nivel acerca de cuáles son las relaciones de preferencia entre las normas interpretativas de segundo nive ${ }^{24}$. Si tengo razón, entonces quienes sostienen una determinada doctrina de la interpretación -es decir, una determinada tesis acerca de cómo debe ser interpretada la ley según el CCCh-incurren en una de estas dos posiciones:

(1) sus tesis, pese a parecer descriptivas, no describen qué dice el derecho sobre cómo aquel debe ser interpretado, sino que nos dicen cómo deberían ser según sus preferencias de política del derecho (tesis político-normativa);

(2) sus tesis pretenden ser descriptivas de qué es lo que prevé el derecho sobre su propia interpretación, pero son falsas dado que el derecho no prevé ninguna norma de tercer grado que ordene los criterios interpretativos de segundo orden ${ }^{25}$ (tesis descriptiva falsa).

Lo que han venido haciendo los intérpretes de los artículos 19 a 24 del CCCh es defender una determinada interpretación -por supuesto posible- de algunos de estos artículos, sosteniendo que hay una regla interpretativa de

\footnotetext{
${ }^{23}$ Constituyen en este sentido deberes alternativos. Aunque aquí no entraré a analizar este aspecto, es, sin embargo, posible (y probablemente más plausible) reconstruir las normas sobre la interpretación -no como normas que califican como prohibido, permitido u obligatorio atribuir un significado-, sino como normas que califican determinados actos (interpretativos) como válidos o inválidos.

${ }^{24}$ Podría pensarse que una de estas normas de tercer nivel (o sobre cómo interpretar los artículos 19 a 24 del CCCh) es una norma implícita. El problema es que si, por ejemplo, afirmamos que existe una norma implícita en favor de la interpretación literal, también se podría afirmar que existe otra norma implícita en favor de la interpretación sistemática. Es decir, los problemas de las reglas intepretativas expresas de segundo nivel se reproducirían en las reglas interpretativas implícitas de tercer nivel.

${ }^{25}$ El problema podría quedar resuelto también de otra manera: si hay alguna norma que nos dijese cómo tenemos que interpretar los artículos 19 a 24 del CCCh. No obstante, nada garantiza que, pese a existir una norma como ésta, los problemas de interpretación desapareciesen. Véase más abajo 3.1.
} 
segundo orden con preferencia absoluta (o una ordenación no vaga ni contradictoria de todos los criterios): en favor del criterio literalista, en favor de una combinación de varias formas de interpretar, o en favor de una interpretación mediada por consideraciones de equidad natura ${ }^{26}$. Ahora bien, para que dicha tesis sea plausible sería necesario probar que existe una meta-regla de tercer orden que señale una regla de segundo orden de preferencia absoluta (o que prescribiera una ordenación no contradictoria ni vaga de las reglas de segundo orden).

Aquí no voy a sostener que dichas tesis carezcan de fundamento: se puede sostener justificadamente que los artículos 19 a 24 del CCCh expresan alguna norma de segundo orden de preferencia absoluta sobre alguno de los criterios interpretativos o normas interpretativas de primer orden (o una ordenación clara y no antinómica de los criterios interpretativos de primer orden). El problema es precisamente que es posible interpretar dichos enunciados de modo que expresen (también o alternativamente) otras meta-normas de segundo orden, que otorguen preferencia absoluta a otras reglas interpretativas de primer orden (u otra ordenación clara de los criterios interpretativos) ${ }^{27}$.

Para que alguna de dichas tesis sobre la interpretación de los artículos 19 a 24 del CCCh resultara ser la única respuesta admisible por el ordenamiento (la única tesis justificada o la tesis verdadera), aquellas deberían probar que existe tal meta-meta-norma de tercer nivel que señale una de las normas de segundo orden tiene una preferencia absoluta (o una ordenación de los criterios no vaga ni antinómica). Es precisamente aquí donde dichas tesis parecen carecer de fundamentación suficiente, y donde incurren en uno de los defectos antes mencionados: bien son tesis filosófico-políticas acerca de cómo debería ser el derecho ${ }^{28}$, bien son tesis descriptivas pero falsas.

\footnotetext{
${ }^{26}$ Aquí es posible remitir a la discusión desarrollada a lo largo de los años por la doctrina civilista chilena. Véase nota 4.

27 Desde un punto de vista más general, es posible afirmar que los artículos 19 a 24 del CCCh permiten derivar, a través de la interpretación de aquellos, diferentes sistemas normativos que regulan todos ellos la interpretación jurídica; esto es, diferentes conjuntos de normas, todas ellas derivables a partir de dichos enunciados, que constituyen interpretaciones plausibles de dichos artículos. El problema es precisamente que no podemos señalar ninguno de esos sistemas alternativos como la interpretación verdadera o correcta de los artículos 19 a 24 del CCCh. Desde luego, sería posible reconstruir los diferentes sistemas de normas sobre interpretación posibles, pero las combinaciones de normas posibles serían tantas que supera con creces los límites de este trabajo.

${ }^{28}$ Desde luego, el hecho de que una tesis sobre cómo debe ser interpretados los artículos 19 a 24 del CCCh tenga carácter filosófico político no es en absoluto un defecto. Es más, al final abogaré en favor de que sea precisamente ésta la dirección que asuma el debate. Lo que sí constituye un defecto es no decir que se trata de una doctrina o tesis de política del derecho o filosófico normativa: presentarlas como tesis acerca de lo que el derecho prescribiría sobre su propia interpretación.
} 


\section{Problemas de interpretación de los artículos 19 a 24 del Código Civil chileno}

A continuación analizaré algunos problemas de interpretación de los artículos del CCCh que versan, justamente, sobre la interpretación de la ley. El objetivo es demostrar que la interpretación de los artículos 19 a 24 del CCCh generan múltiples problemas interpretativos, de manera tal que se muestre con claridad que cualquier tesis que pretenda mostrar alguna de dichas interpretaciones como la única posible (la verdadera o la correcta) debería demostrar la validez (o aplicabilidad) de una meta-meta-norma de tercer nivel. Aquí no intentaré demostrar como toda doctrina de la interpretación falla al intentar demostrar la existencia de una tal norma pues excede los límites de este trabajo y, porque resulta extremadamente complicado probar la no existencia de una norma.

Los problemas de interpretación de los artículos 19 a 24 del CCCh pueden ser agrupados en tres categorías:

a) en primer lugar, problemas respecto a qué reglas interpretativas son las expresadas por cada uno de los enunciados comprendidos entre los artículos 19 y 24 del CCCh (problemas sobre las reglas de interpretación de primer orden formuladas). Se trata de problemas tanto de ambigüedad de dichos enunciados como de vaguedad de algunas de las posibles normas establecidas por aquellos;

b) en segundo lugar, problemas acerca de las relaciones de preferencia entre las normas interpretativas de primer nivel, es decir, problemas relativos a las meta-normas o reglas de interpretación de segundo nivel expresadas en tales enunciados. Se trata en este caso de problemas de vaguedad de dichas normas y de antinomias entre aquellas;

c) en tercer lugar, pueden encontrarse otros problemas que no son de interpretación en sentido estricto (de atribución de significado a los enunciados normativos) de dichos artículos pero que resultan relevantes en relación al objeto de regulación de los artículos 19 a 24 del CCCh.

Expondré dichos problemas en el mismo orden en los que surgen con base en la lectura ordenada del propio texto del CCCh. La razón es que me parece una forma ordenada que tiene la virtud de poder dar cuenta de manera precisa de los diferentes problemas que genera cada uno de los artículos en cuestión del CCCh. Una última advertencia: aunque es mi intención, no estoy nada seguro de estar presentando una lista exhaustiva de los problemas de interpretación que surgen de estos artículos, siendo posible que un ojo más avezado que el mío encuentre alguno(s) más.

\subsection{Circularidad o autorreferencialidad}

El primer problema que hay que señalar respecto de la interpretación de los artículos 19 a 24 del CCCh es que parece plausible pensar que las normas 
que expresan tales artículos son aplicables también a la interpretación de sí mismos. Es decir, que para saber cómo hay que interpretar dichos artículos, ya deberíamos haber atribuido significado a dichos enunciados y saber cuáles son las normas que ellos mismos expresan. Ello conduce obviamente a un problema de circularidad o autorreferencialidad; problema, por lo demás, irresoluble.

Alguien podría pensar que esta primera objeción es gratuita y descontada: primero por ser evidente, y segundo porque en realidad no tiene ninguna incidencia práctica. La objeción no es, no obstante, ni gratuita ni descontada precisamente porque algunas de las más acreditadas doctrinas sobre la interpretación de dichos artículos están basadas en un determinado criterio interpretativo. Me refiero a tesis como aquellas de Guzmán Brito ${ }^{29}$, quien sostiene una determinada interpretación de los artículos del CCCh a la luz de la historia dogmática de aquellos.

Ahora bien, no hay en el texto del propio CCCh enunciado alguno que permita afirmar, incluso en el caso de que dicha historia dogmática fuera plausible ${ }^{30}$, que debamos atribuir significado a dichos enunciados a la luz de su historia dogmática. No estoy afirmando, por supuesto, que tal alternativa sea incorrecta, sino que junto a esta interpretación basada en la historia dogmática del CCCh es posible realizar también otras interpretaciones igualmente justificadas, y que conducen a una interpretación-producto diferente de dichos enunciados.

\subsection{El objeto de la regulación: la "ley"}

El segundo problema que nos encontramos a la hora de atribuir significado al texto del CCCh aparece tanto en el nombre del título como en la primera oración del artículo 19. En efecto, el título se Ilama "Interpretación de la ley" y la primera oración del artículo 19 afirma que "Cuando el sentido de la ley es claro $[\ldots]^{\prime \prime}$.

Pues bien, el segundo problema de interpretación que nos encontramos es que no sabemos si cuando el CCCh habla de "ley" debemos entender la totalidad de los textos jurídicos, incluida la Constitución, los Autos acordados, y los Decretos Supremos, o si, por el contrario, debemos entender que las normas contenidas en dichos artículos son aplicables únicamente a los enunciados aprobados bajo el procedimiento para la creación de leyes.

\footnotetext{
${ }^{29}$ Véase GuZmán (1992). Para un mayor desarrollo de sus tesis en materia de interpretación, véase GuZMÁn (2007).

${ }^{30}$ Para una crítica de la reconstrucción de las normas del Código Civil como herederas, a través de Bello, del pensamiento de Jean Domat, véase BAsCuñán (2013), pp. 32 y ss.
} 
Es preciso señalar, no obstante, que aunque consideremos que dichas normas solo serían aplicables a las disposiciones con rango de ley, el problema no estaría aún resuelto. La razón es que no sabemos si por "ley" debemos entender solo las leyes en sentido estricto ("ley" en sentido formal), o si por el contrario debemos entender cualquier norma con rango de ley ("ley" en sentido material). Ambas interpretaciones son posibles y plausibles, no pudiendo encontrarse una única solución (y no parece que el artículo 1 del propio CCCh sea de ayuda a este respecto $)^{31}$.

\subsection{Sentido claro versus tenor literal}

Como es sobradamente conocido, la dogmática civilista chilena ha introducido una distinción entre el tenor literal de un texto y su sentido claro, declarando una parte de la doctrina que ambas no deben ser entendidas en el mismo sentido.

Según Ducci Claro ${ }^{32}$, es posible que encontremos textos en los que el tenor literal no coincide con su sentido claro u obvio: mientras que el primero se referiría únicamente a la interpretación con base en el criterio literal, cuál sea el significado del segundo no es del todo claro ni pacífico.

Para algunos, el sentido claro y obvio sería el resultado del uso de los cuatro criterios interpretativos clásicos presentados por Savigny y del uso de los criterios subsidiarios para la interpretación de leyes defectuosas, también de Savigny ${ }^{33}$; otros parecen en ocasiones remitirlo a la intención del intérprete ${ }^{34}$, en ocasiones leída a la luz de la equidad natural entendida como ratio scripta de la doctrina ${ }^{35}$. Aunque, finalmente, para otros la distinción podría ser asimilada a aquella entre interpretación objetiva y subjetiva, o a aquella entre interpretación con base en criterios lingüísticos y criterios pragmáticos ${ }^{36}$.

No obstante, en referencia a este sentido claro como diverso del tenor literal, si lo consideramos como el resultado de la aplicación conjunta de varios criterios, se podría objetar que, si de varios criterios se trata, su aplicación podría conducir a resultados interpretativos diversos, no estando claras las relaciones de

\footnotetext{
31 El artículo primero del CCCh reza lo siguiente: "La ley es una declaración de la voluntad soberana que, manifestada en la forma prescrita por la Constitución, manda, prohibe o permite".

32 Duccl (1977), p. 91.

33 Según Claro Solar para determinar el significado obvio sería necesario emplear todos los criterios establecidos por los artículos 19 a 22, de manera conjunta y coordinada. Véase Claro (1898), p. 124.

34 Esta parece ser la tesis de Alfonso Paulino. Véase Alfonso (1892), pp. 9 y ss.

35 Esta parece ser la tesis defendida por Guzmán Brito. Véase Guzmán (1991), pp. 70 y ss.

${ }^{36}$ Antonio Bascuñán parece sostener esta tesis. Véase BAscuñÁn (2013) p. 13.
} 
preferencia entre los mismos ${ }^{37}$. Si la interpretación consiste en la aplicación de reglas, y dichas reglas pueden -como de hecho sucede en muchas ocasionesconducir a resultados interpretativos contrastantes, entonces no se ve cómo se puede -o qué significa- utilizar conjuntamente varios criterios ${ }^{38}$.

Sea como fuere, el problema interpretativo parece subsistir porque podemos interpretar la primera oración del artículo 19 de manera que "sentido (...) claro" y "tenor literal" signifiquen lo mismo o signifiquen cosas diversas. De nuevo, las dos interpretaciones parecen plausibles ya que ambas parecen contar con bases textuales, pero ninguna lo suficientemente sólida como para poder descartar otras alternativas.

\subsection{Tenor literal: ¿preferencia absoluta o relativa?}

Aún en la primera oración que constituye el artículo 19 se puede leer "que no se desatenderá su tenor literal". Este inciso parece constituir una norma de interpretación de segundo nivel de preferencia, es decir, una norma que establecería que habría que dar preferencia al tenor literal frente a cualquier otro tipo de interpretación ${ }^{39}$.

Sin embargo, es perfectamente posible (y estaría justificado) interpretar este inciso afirmando que, antes que establecer una meta-norma de preferencia absoluta (aunque con una lista de excepciones explícitas), se trata de una norma que permite al intérprete del texto desplazar el tenor literal en favor de otro cuando se den razones suficientemente relevantes para ello ${ }^{40}$ (meta-norma de preferencia relativa). La obligación, antes que de usar siempre el criterio de interpretación literal (salvo para las excepciones explícitas), sería de no "desatender", esto es, consistiría en tomar en cuenta la interpretación producto obtenida con base en el criterio literalista. Interpretada de esta segunda manera, dicha

\footnotetext{
${ }^{37}$ En contra de esta tesis, merece la pena citar la famosa afirmación de Claro Solar, según el cual: [N]o son cuatro clases de interpretación entre las cuales se pueda elegir, según el gusto y capricho de cada cual: son solo cuatro operaciones diversas, cuya reunión es indispensable para interpretar la ley". Confróntese Claro (1898), p. 124.

38 A esto es a lo que me refiero cuando afirmo que la convención sobre la interpretación de los artículos 19 a 24 puede ser una convención no clara. Véase nota 19.

${ }^{39}$ Esta sería, según Bascuñán, la tesis de Chacón y Armas. Véase Bascuñán (2013), n. 65.

${ }^{40}$ Esta posibilidad ya parece haberla tenido en cuenta tempranamente Paulino Alfonso, quien sostiene que en ocasiones tal vez la literalidad deba ceder ante otros criterios. No obstante, afirma que cuando la interpretación literal conduzca a absurdos resulta conveniente solicitar un cambio legislativo. Confróntese AlFONSO (1892), pp. 10-11. Parece ser también la tesis de Cood y Fabres, quienes consideraban que esta interpretación debía ceder cuando nos encontramos ante resultados interpretativos absurdos. También pueden ser entendidas en este sentido las tesis de Claro Solar.
} 
regla establecería una preferencia por el tenor literal pero dicha preferencia sería únicamente relativa.

Bajo la primera interpretación, el enunciado expresaría una meta-norma interpretativa que impide tener en cuenta cualquier otra interpretación de un determinado enunciado; bajo la segunda, se establecería una preferencia por la interpretación literal que podría ser desplazada en el caso de que aparezcan razones normativas lo suficientemente importantes. Por supuesto, cuándo un conjunto de razones normativas relevantes sea lo suficientemente importante como para desplazar justificadamente a esta interpretación no es claro, ni es algo que parezca que podamos identificar exhaustivamente a priori. Tampoco está claro si se establece una relación de preferencia absoluta o relativa.

\subsection{Problemas relativos a la interpretación literal}

Más allá de los problemas vistos hasta ahora, parece que el primer inciso del artículo 19 consagra el criterio o norma interpretativa de la interpretación literal. Si bien en su segundo inciso parece prever que la interpretación literal no siempre resulte satisfactoria (posibilidad de oscuridad), lo cierto es que la interpretación literal presenta muchos más problemas de lo que normalmente se admite.

Cuando se habla de interpretación literal de lo que se está hablando es de interpretación con base en las normas lingüísticas convencionales ${ }^{41}$ de un lenguaje natural. Dicho en términos extremadamente sencillos (aunque simplificadores), las normas lingüísticas pueden ser divididas en tres tipos: (a) semánticas, o sobre el significado de los términos; (b) sintácticas, o sobre la forma y orden en los que usar los términos o palabras; (c) pragmáticas o (meta-)normas que versan sobre los dos anteriores tipos de normas, y que servirían para elegir entre usos alternativos de aquellas.

Pues bien, contra lo que se suele pensar, lo cierto es que la interpretación literal -entendida como aquel significado atribuido por las reglas del lenguaje natural- es mucho más problemática de lo que pudiera parecer ${ }^{42}$. En primer lugar, porque el lenguaje natural es frecuentemente ambiguo, pudiendo atribuirse a los enunciados diferentes significados. Es, en segundo lugar, un lenguaje vago, en el sentido de que los significados que el lenguaje natural atribuye a

\footnotetext{
${ }^{41}$ Que una norma sea convencional supone que aquella tiene tres características: primero, su contenido es irrelevante desde el punto de vista moral; segundo, nace del comportamiento convergente; y tercero, la principal razón para seguir aquella es que el resto de sujetos se adapta a tal norma. Para una análisis del convencionalismo, véase AreNA (2014).

42 Para una defensa del literalismo, véase IturRALDE (2014).
} 
términos y enunciados es poco preciso, Ileno de condiciones de uso no claramente delimitadas.

No obstante, alguien podría argüir que son las reglas de la pragmática del lenguaje las que nos permiten desentrañar el significado literal de los términos. El segundo problema consiste precisamente en que se ha sostenido que las normas pragmáticas del lenguaje son dependientes de los contextos de interpretación, no siendo posible establecer exhaustivamente a priori cuáles son las reglas pragmáticas aplicables y, por tanto, cuál es el significado a atribuir a los enunciados. Según las teorías relativistas no indicales y las teorías expresivistas del lenguaje ${ }^{43}$, el significado literal de un texto es relativo o dependiente del contexto de interpretación, no siendo posible establecer su significado antes de que se presente una ocasión para su aplicación.

\subsection{La intención del legislador y el espíritu de la ley}

En el segundo inciso del artículo 19 se afirma que "para interpretar una expresión obscura de la ley, [bien se puede] recurrir a su intención o espíritu". Esta oración provoca diferentes problemas interpretativos.

Dicho enunciado parece introducir un criterio de interpretación de primer orden, para atribuir significado a los textos normativos toda vez que haya una expresión obscura. No obstante, lo que no está claro es qué es exactamente lo que autoriza ni cuándo lo autoriza.

En primer lugar, no resulta extensionalmente claro cuándo se puede recurrir a la intención o espíritu. Es decir, aunque pueda resultar claro cuándo intensionalmente podemos recurrir a la intención o espíritu (cuando "una expresión [es] obscura" ${ }^{\prime 4}$ ), esto puede resultar insuficiente para determinar cuándo extensionalmente -en qué casos concretos- hay que recurrir a esta interpretación, ya que los márgenes entre los significados claros y los significados oscuros son, a su vez, oscuros. Dicho de otro modo: si se trata de una cuestión de vaguedad, el problema es que tampoco nos ponemos de acuerdo acerca de cuándo un significado es oscuro dado que los contornos de la zona de vaguedad son también ellos oscuros (o vagos).

Pero, en segundo lugar, no sabemos si por "intención" y "espíritu" debemos entender dos cosas diferentes o si, en relación a lo que se autoriza, por el contrario, debemos entenderlas como expresiones sinónimas. Si "intención" y "espíritu" se refieren a cosas diferentes, entonces surge el problema de la

43 Kristan y Pravato (2015).

44 Dicho sea de paso: la oscuridad se puede predicar no de las expresiones o de cualquier otra entidad lingüística, sino que se puede predicar de los significados, de los contenidos proposicionales. 
preferencia entre estos dos criterios, no sabiendo cuál de los dos debe ser aplicado o preferido sobre el otro. Si, por el contrario, intención del legislador y espíritu de la ley son lo mismo, no es en absoluto claro en qué consiste este criterio.

\subsection{La intención de la ley: ¿qué intención?}

Supongamos, por hipótesis, que la intención de la ley es algo diferente del espíritu de aquélla. Pues bien, más allá de los argumentos normativos que se podrían esgrimir en contra de la interpretación intencionalista ${ }^{45}$, existen múltiples dificultades para establecer cuál sería la interpretación conforme a la intención -suponemos- del legislador. Mencionaré solo algunas de ellas de carácter ontológico y epistémico.

La primera es que, cuando los textos son aprobados por entidades colectivas o colegiadas, como lo son las Cámaras de representantes, resulta extremadamente complicado hablar de "intención del legislador". La razón es que la intención o las intenciones normalmente las predicamos de la conducta de individuos, no de los órganos colegiados ${ }^{46}$. Ello porque la intención parece, bien un estado mental, bien la razón que tiene un sujeto para llevar a cabo una acción. Hablar pues de la intención de un órgano colectivo resulta, en el mejor de los casos, solo una metáfora ${ }^{47}$. A ello hay que añadir que, en los modernos estados constitucionales de derecho, no es normalmente una asamblea la que aprueba los textos normativos, sino que son varios los órganos que intervienen en su elaboración. Esto sin duda añade una dificultad ulterior para hablar de la intención de la ley.

En segundo lugar, se podría sostener que si bien son los sujetos los que pueden tener intenciones, lo cierto es que es posible que una colectividad de sujetos tenga una intención común. Desde luego, esto podría sostenerse pero resulta bastante difícil hablar de una intención compartida de los sujetos de un órgano político colegiado. Se trata de un problema que no es de ningún modo exclusivo de Chile, sino que en todas las democracias parlamentarias se producen fenómenos como el voto de intercambio, el desconocimiento de los

\footnotetext{
45 Para una defensa del intencionalismo, véase MARMOR (1995). Para una defensa más teórica que práctica, Véase RAZ (1997).

${ }^{46}$ Merece la pena Ilamar la atención sobre que Paulino Alfonso, comentando el significado del artículo 19, dice explícitamente que "[E]se a que sea reconocido y acatado el verdadero pensamiento del legislador". Es decir, identificar el criterio literal con el intencional, pese a que en otros pasajes relativos al mismo artículo rechaza el uso de la intención. No obstante, también introduce como parte del criterio literal, el criterio sistemático. Véase Alfonso (1892), pp. 5 y 7.

47 Olivecrona (1980), cap. II.
} 
parlamentarios sobre qué están aprobando, representantes que votan porque su grupo parlamentario les dijo que votaran a favor de un texto, etc. En estos casos, la única intención que es posible encontrar es la de aprobar un texto, pero no necesariamente sobre su significado ni sobre los efectos que se quieren alcanzar con tal texto. Dicha intención resulta inútil para la interpretación del derecho.

En tercer lugar, cuando usamos la expresión "intenciones", no siempre somos conscientes de que en realidad se puede usar dicha expresión para hacer referencia tanto a los objetivos o fines más inmediatos (como que haya un texto jurídico que diga determinadas cosas) como a fines bastante mediatos (como el significado a atribuir al texto, los cambios sociales que se pretenden generar mediante las anteriores "intenciones", etc. $)^{48}$. En realidad, cuando usamos el término "intención" podemos estar haciendo referencia al menos a dos cosas diferentes: la voluntad de incorporar al ordenamiento una norma (o solo un texto normativo) y la voluntad de alcanzar determinados resultados prácticos. En el primer caso, el criterio intencionalista tiende a confundirse con el criterio originalista, mientras que en el segundo genera un problema entre las intenciones mediatas e inmediatas del legislador. En efecto, cuando los sujetos Ilevamos a cabo acciones normalmente proyectamos objetivos más cercanos y más lejanos que queremos alcanzar. Cuál sea la intención que debemos elegir para establecer la interpretación es cuestión discutida, conduciendo aquellas a diferentes interpretaciones-producto.

En cuarto lugar, si las intenciones son estados mentales, parece poco discutible que no tenemos acceso a dichos estados mentales pues no tenemos la posibilidad de observar qué es lo que sucede en las cabezas de los legisladores cuando deciden aprobar un texto normativo. Si, por el contrario, entendemos que es algo diferente de un estado mental, y es aquello que anima la acción de un sujeto (una razón), tampoco está claro que tengamos un acceso inmediato a aquella. Más bien parece tratarse de reconstrucciones, difícilmente -cuando no imposibles- de verificar, problema por lo demás común a la mayoría (o a la totalidad) de las ciencias sociales.

\subsection{El "espíritu" de la ley}

Supongamos, por hipótesis, que el espíritu de la ley sea algo distinto a la intención de quien creó la norma. Lo primero que nos tenemos que preguntar es qué sería esta entidad Ilamada "espíritu de la ley". Se trata, parece claro, de una metáfora.

${ }^{48}$ Véase Lifante (1999). Creo, no obstante, que el mejor ejemplo de ello se encuentra, antes que en las leyes, en las constituciones. 
Como metáfora, aquella del espíritu de la ley parece hacer referencia a las razones que servirían para justificar, más allá de su autor, la presencia de una norma ${ }^{49}$. Es decir, no a las razones que animaron la conducta de un sujeto de carne y hueso (su autor o cualquier otro sujeto), sino aquellas que justificarían normativamente la existencia de la norma.

Pero, por desgracia, no abandonamos todavía el ámbito de las metáforas. A menos que suscribamos alguna suerte de objetivismo moral monista (o irenista) ${ }^{50}$, lo cierto es que no parece posible establecer cuál es la justificación o espíritu de una norma. La razón es que diferentes sujetos pueden realizar diferentes reconstrucciones, varias de ellas plausibles, para establecer cuáles son las razones que justifican la presencia de una norma. Si hay diferentes justificaciones de una norma en competición, a menos que exista alguna que sea correcta o se corresponda con la moral objetiva, no parece que existan criterios para elegir entre ellas ${ }^{51}$.

Nótese, por último, que para interpretar el enunciado de conformidad a su espíritu, ya deberíamos saber qué dice o cuál es el contenido del enunciado normativo: para saber cuál es el objetivo o espíritu de la norma, primero tendríamos que saber de qué norma estamos hablando. Se trata, por tanto, de una norma sobre interpretación inútil por ser circular ya que para interpretar un enunciado conforme a su espíritu, primero deberíamos saber qué norma expresa aquél, es decir, ya deberíamos haberlo interpretado. No podemos establecer cuál es la justificación de una norma sin saber previamente de qué norma estamos hablando.

\subsection{La historia fidedigna de la ley}

El último inciso del segundo párrafo del artículo 19 introduce una referencia a la historia fidedigna de la ley: "recurrir a su intención o espíritu, claramente

\footnotetext{
49 Francisco Laporta ha sostenido que ésta debe ser la forma en la que interpretemos las leyes en el ordenamiento español: interpretación objetiva. Véase LAPORTA (2007), cap. VIII.

${ }^{50}$ Por objetivismo moral entiendo la tesis según la cual existen criterios objetivos de corrección práctica, es decir, parámetros morales o ético-políticos cuya corrección no depende de la preferencia de los sujetos (de ningún sujeto). Por monismo entiendo la tesis según la cual nuestros valores morales o ético-políticos tienen una estructura jerarquizada, situándose en el escalón más alto un único valor (o hay un solo valor). Por irenismo entiendo la tesis según la cual los valores son múltiples pero cada uno tendría su campo de aplicación autónomo, no produciéndose conflictos entre ellos. Si suscribimos la primera y la segunda o la tercera de estas tesis -las cuales me parecen, por lo demás, erróneas- se podría defender que hay una sola justificación para cada norma. Si se niega cualquiera de las anteriores, entonces sería posible encontrar diferentes justificaciones ("espíritus") de una misma norma.

${ }^{51}$ Es suficiente con hacer referencia a las funciones que cumpliría la pena -resocializadora, prevención general, prevención especial, retributiva, etc.- asociada a un determinado tipo penal para darse cuenta de lo difícil que resulta establecer cuál sea el espíritu de una ley.
} 
manifestados en ella misma, o en la historia fidedigna de su establecimiento". Parece tratarse de una referencia a los instrumentos que se pueden utilizar para establecer la intención y/o espíritu de la ley. No queda claro si, en el caso de que intención y espíritu sean cosas diferentes, si la historia fidedigna es relevante para determinar ambos (especialmente el espíritu).

La expresión "historia fidedigna de la ley" puede, sin embargo, hacer referencia a dos cosas diferentes: bien a algún documento incorporado al texto legal (o adjunto a su tramitación), o bien a cualquier documento o información histórica fiable que tengamos. En el caso de que se admitan más instrumentos que algún texto vinculado a su tramitación, obviamente surge la dificultad de establecer cuándo un texto es fiable.

Refiriéndome solo al primero de los dos anteriores sentidos -es decir, por historia fidedigna de la ley debemos entender solo algún (o algunos) documento(s) adjunto(s) a la tramitación del texto legal-es posible que dicho enunciado haga todavía referencia a dos objetos diferentes. En primer lugar, el texto denominado Historia de la Ley, elaborado por la Biblioteca del Congreso Nacional. En segundo lugar, puede hacer referencia al Mensaje de la ley, es decir, a aquel texto en el que se hace mención a las razones que han Ilevado al Presidente a presentar el proyecto de ley.

En relación al primero de ellos, conviene señalar que la Historia de la ley raramente muestra un itinerario inequívoco, en el sentido de que es posible que se encuentren argumentos contradictorios en las declaraciones reflejadas en aquella. Es posible, en este sentido, que la Historia de la ley muestre "votos concurrentes", esto es, que diferentes representantes votaron los mismos textos por razones diferentes. Además, si pensamos que la Historia de la ley no constituye la transcripción exacta de lo dicho (y hecho) por cada representante, lo cierto es que sería un poco ingenuo pensar que aquella constituye un reflejo exacto de lo que pensaba cada una de las personas implicadas en su discusión y aprobación ${ }^{52}$.

En relación al segundo documento, el Mensaje de la ley, es preciso advertir dos cosas. Por un lado, que el Mensaje se incorpora al texto legal solo excepcionalmente y cuando la iniciativa legislativa ha sido ejercida por la Presidencia de la República, pero no cuando el texto ha sido tramitado por iniciativa de una de las cámaras. Por el otro, frecuentemente la tramitación de la ley termina modificando el texto original con el que comenzó la tramitación parlamentaria, por lo que no resulta extraño pensar que pueda haber importantes disonancias justificativas entre el texto finalmente aprobado por las Cámaras y el mensaje presidencial.

${ }^{52}$ En otro caso supongo que la Biblioteca Nacional del Congreso habría conseguido acabar con el problema de la neutralidad y de la cientificidad en la disciplina de la Historia. 


\subsection{Sentido natural (y obvio) y sentido técnico-jurídico}

La primera oración del artículo 20 señala que "Las palabras de la ley se entenderán en su sentido natural y obvio, según el uso general de las palabras". El primer problema que genera esta oración es si esta primera oración del artículo 20 introduce alguna norma nueva respecto del artículo anterior. Más allá del significado que le atribuyamos a la expresión "sentido natural y obvio", si aquella tiene un significado diferente del sentido literal -como sostiene Ducci Claro-el problema es que seguimos sin saber qué relaciones de preferencia existirían entre las normas expresadas por estos enunciados: si tenemos que preferir el tenor literal o el sentido natural y obvio.

El segundo problema relativo a la interpretación de esta primera oración del artículo 20 es si está estableciendo una distinción entre el lenguaje natural (u ordinario) y el lenguaje técnico de los juristas y, en caso afirmativo, si está estableciendo una relación de preferencia del primero respecto del segundo. Además, en caso de que así fuera, sería necesario establecer si la prioridad que se establece es relativa o absoluta. En este último caso, se debería descartar el uso técnico o las definiciones dogmáticas de conceptos jurídicos tales como delito, acto administrativo, etc., en favor del significado que se le atribuyen a estos términos en el lenguaje ordinario o habitual ${ }^{53}$. Desde luego, se trata de una interpretación posible y plausible, pero también lo es la interpretación contraria según la cual dicha distinción no puede ser encontrada en el artículo 20.

\subsection{Las definiciones legales}

La segunda oración del artículo 20 afirma que "cuando el legislador las haya definido [las palabras de la ley] expresamente para ciertas materias, se les dará en éstas su significado legal". Este enunciado parece expresar una norma interpretativa de primer orden para atribuir a un fragmento de un texto normativo el significado que le ha atribuido el propio legislador de manera expresa mediante una definición. Sin embargo, esta regla en realidad no sirve para atribuir significado a ningún enunciado, sino que remite a una definición -es decir, a otro enunciado- dada por el propio legislador para dotar de sentido a un término ${ }^{54}$.

Es posible preguntarse cómo se relaciona dicho criterio interpretativo con el resto de criterios interpretativos hasta aquí vistos. En este sentido, es posible afirmar que el enunciado en cuestión expresa, también, una metanorma interpretativa de segundo orden de preferencia absoluta en favor de las definiciones legales. Sin embargo, también puede considerarse que este

53 No creo que sea necesario señalar los problemas que ello generaría.

54 Se trata en este sentido de una variante de la interpretación sistemática. 
enunciado expresa una norma de preferencia pero únicamente relativa que podría ceder en algunos casos. Cuáles fueran estos casos sería obviamente cuestión controvertida.

Además de este primer problema, surgen otras dos dificultades en relación a la atribución de significado de esta oración. El primero de ellos es cómo tenemos que interpretar las propias definiciones legales, pues también a aquellas, como a todo enunciado, es preciso dotarlas de significado. Como ya se ha dicho, este criterio no permite atribuir significado a ningún texto sino que lo que hace es remitirnos a otro texto que es preciso interpretar.

El segundo problema es que también es problemática la extensión o la aplicabilidad de dicha norma. En concreto, no se sabe si las definiciones legales son aplicables únicamente dentro del mismo texto legal (ley) en el que aparece la definición, si únicamente al título o sección en el que se define la palabra, o si dicha definición debe ser extendida a la totalidad del ordenamiento (o solo a algunas materias pero no a otras). Como se verá en relación a la interpretación sistemática (véase más abajo 3.14), surge además el problema de si una definición legal que aparece en un texto que expresa normas de rango jerárquico inferior puede ser empleada para dotar de significado a textos jerárquicamente supra-ordenados.

\subsection{Las palabras técnicas de toda ciencia o arte}

La primera oración del artículo 21 reza lo siguiente: "Las palabras técnicas de toda ciencia o arte se tomarán en el sentido que les den los que profesan la misma ciencia o arte". Este enunciado, del mismo modo que aquel que acabamos de analizar en el parágrafo anterior, parece expresar una norma interpretativa de primer orden para atribuir a un fragmento de un texto normativo el significado atribuido por alguna disciplina.

El primer problema que genera este enunciado y la introducción de la respectiva regla interpretativa es su relación con las otras reglas de preferencia que hemos visto: los términos definidos por el legislador y los sentidos natural (u obvio) y literal. Cuál sea la relación de dicha regla interpretativa con las anteriores no es de ningún modo obvio.

El segundo problema es determinar si la dogmática jurídica está incluida entre estas artes y ciencias a las que se refiere el CCCh. Por supuesto, ésta no es la sede para discutir si la dogmática jurídica debe ser considerada una ciencia o un $\operatorname{arte}^{55}$. Sin embargo, no parece descabellado afirmar que este enunciado puede ser interpretado de manera tal que se dé preferencia -en el problemático

${ }^{55}$ En materia, me permito remitir a NúÑEZ (2014b); NúÑEZ (2014c). 
sentido explicado en el párrafo anterior- a las elaboraciones de los estudiosos del derecho positivo.

En tercer lugar, tanto si consideramos que ciencia y arte son términos no sinónimos como si significan cosas diferentes, es posible preguntarse si algunas disciplinas pueden ser empleadas para atribuir sentido a la ley, pues difícilmente pueden ser considerados como artes, y es más que discutible que se trate de ciencias (al menos según algunos de los criterios de cientificidad disponibles). Por poner solo un ejemplo banal, es posible preguntarse si los términos económicos que aparecen en los textos normativos deben ser interpretados tal y como los define el estudio de la economía, la cual según muchos autores está lejos de ser una disciplina científica.

En cuarto lugar, y vinculado con el anterior punto, resulta ingenuo pensar que en las disciplinas científicas exista unanimidad en el uso de las palabras. Por el contrario, especialmente las ciencias humanas y sociales, aunque no solo, existen fuertes desacuerdos acerca de qué significa, por ejemplo, "sociedad", "ideología", "género" o "acción". Los desacuerdos sobre cómo definir buena parte de los conceptos dogmáticos son solo un ejemplo, y no la excepción, de los desacuerdos sobre cómo definir los conceptos que se dan en las disciplinas sociales.

\subsection{3. ¿Excepción al sentido artístico o científico? ¿Remisión al originalismo?}

La segunda oración del artículo 21 -"a menos que aparezca claramente que se han tomado en sentido diverso" - podría ser interpretada como si introdujese una excepción explícita a la primera oración del mismo artículo, al menos cuando esta última es interpretada como una norma interpretativa de segundo orden que establece una preferencia en favor del significado científico o artístico de determinadas disciplinas. Cuál sea el carácter de dicha excepción, si absoluta o relativa, es cuestión que podría ser argumentada en ambos sentidos.

No obstante, también se podría argüir que dicha oración no añade nada nuevo respecto a lo ya expresado en el artículo 19, que afirma que se debe dar preferencia al sentido claro. En tal caso, se podría afirmar que existe una relación jerárquica entre las normas interpretativas de segundo orden literal y técnica, en el sentido de que habría que emplear preferentemente la primera. Sin embargo, es posible controvertir esta tesis afirmando que la excepción introducida por la segunda oración del artículo 21 se refiere no ya al significado literal, sino a cualquier significado que aparezca claramente como el sentido que ha "tomado" el enunciado.

Hay que añadir que esta última referencia -en concreto, el uso de la expresión "tomado": "a menos que aparezca claramente que se han tomado en un sentido diverso" - introduce la posibilidad de interpretar dicho enunciado 
de manera diversa. En efecto, podría interpretarse que la referencia es -no al sentido literal, natural u obvio del término o expresión-, sino a la intención del legislador entendida como la voluntad de que se emplearan sus términos tal y como los ha entendido, según el significado que quería atribuir a sus expresiones, quien ha "tomado" sus propias palabras en un determinado sentido. De este modo, nos encontraríamos con una preferencia originalista sobre el sentido técnico, pero cuya relación con el literalismo supuestamente prescrito en el artículo 19 no sería clara.

\subsection{El contexto de la ley y los argumentos sistemáticos}

El primer inciso del artículo 22 reza lo siguiente: "El contexto de la ley servirá para ilustrar el sentido de cada una de sus partes, de manera que haya entre todas ellas la debida correspondencia y armonía". Pese a su aparente claridad, este artículo genera varios problemas de interpretación.

El primero de ellos es cuál sea la relación de preferencia con el resto de criterios interpretativos: si está en el mismo plano que la interpretación literal, natural u obvia, técnica, científico-artística, o si existen relaciones de preferencia con aquellos (y qué tipo de relación de preferencia).

El segundo de ellos se refiere al significado de la expresión "contexto de la ley". En efecto, la expresión "contexto de la ley" podría ser interpretada de maneras diferentes, como si expresara alguna de las siguientes normas (o algunas de ellas conjuntamente, o todas).

a) Podría, en primer lugar, ser considerada como una reiteración del criterio intencionalista, o una remisión al criterio histórico, ya que el "contexto de la ley" podría referirse a las condiciones sociales en las que se aprobó el texto normativo a interpretar y a los objetivos que el legislador intentaba alcanzar. Es decir, aquí contexto de la ley no significaría contexto lingüístico, sino el contexto social de aprobación de la ley, a las circunstancias políticas en las que se aprobó.

b) Podría, en segundo lugar, ser considerada como una nueva consagración del criterio originalista, ya que la expresión "contexto de la ley" podría ser interpretada como una referencia al contexto lingüístico de aprobación: a las reglas lingüísticas vigentes al momento de la interpretación de la emanación del texto.

c) Podría, en tercer lugar, ser entendida también como la consagración del criterio sistemático. Sin embargo, el criterio sistemático, antes que un solo criterio, constituye en realidad un conjunto de criterios que pueden conducir a diferentes resultados interpretativos.

Si adoptamos esta última interpretación según la cual tal artículo consagra el criterio sistemático de interpretación, el problema es que, en realidad, no 
es un criterio interpretativo ${ }^{56}$, sino un conjunto de al menos tres diferentes criterios que pueden llevar a diferentes resultados interpretativos. Por poner solo un ejemplo, los criterios interpretativos sedes materiae y el de la constancia terminológica pueden conducir $-y$ conducen frecuentemente- a resultados interpretativos diferentes. El problema, claro está, es que no sabemos cuáles de dichos criterios interpretativos sistemáticos son los incorporados por el primer párrafo del artículo 22.

La atribución de significado al artículo 22 del CCCh genera al menos un problema más. Se trata del significado a atribuir a las expresiones "correspondencia y armonía". Cuando, en el ámbito jurídico, se habla de correspondencia y/o armonía, podemos estar haciendo referencia a tres cosas diferentes:

i) en primer lugar, la coherencia lógica, entendida como ausencia de normas que impliquen la atribución de calificaciones jurídicas incompatibles a una misma conducta;

ii) en segundo lugar, la coherencia axiológica, esto es, la ausencia de conflictos en el plano de las razones subyacentes de las normas;

iii) por último, la coherencia instrumental, en el sentido de que unas normas son instrumentos para dar satisfacción a otras normas.

Cuál de estos sentidos sea (o sean) el (o los) que debemos adoptar para la interpretación del artículo 22 es algo discutible, pudiendo conducir la adopción de uno u otro a resultados interpretativos diversos.

\subsection{Interpretación intertextual}

El segundo párrafo del artículo 22 afirma lo siguiente "Los pasajes obscuros de una ley pueden ser ilustrados por medio de otras leyes, particularmente si versan sobre el mismo asunto". Este párrafo puede ser interpretado, en primer lugar, como una explicación o aclaración de la norma expresada en el párrafo primero del artículo 22, limitando el alcance de la interpretación sistemática solo a textos oscuros y solo a la interpretación intertextual. Pero, puede, en segundo lugar, ser leído como una norma independiente (o parcialmente independiente) que incorpora un criterio interpretativo específico.

En el primer caso, el segundo inciso vendría a limitar el alcance del primero: la interpretación -precisamente sistemática- de ambos lleva a pensar que la interpretación sistemática está permitida solo en aquellos casos en los que el significado sea oscuro y solo en su versión intertextual. En el segundo caso, por el contrario, no sabríamos cuándo está permitida la interpretación sistemática en términos generales (lo que podría llevar a pensar, interpretando a contrario,

56 TARello (2013), p. 337. 
que lo está siempre), pero sí que la interpretación de leyes con base en otras leyes está permitida solo cuando el texto de la ley a interpretar sea obscuro.

Surge, a continuación, el problema de qué debemos entender por "ley". Aquí se vuelven a reproducir los problemas analizados anteriormente (véase más atrás 3.2). Cabe además preguntarse si es posible dotar de significado a un texto que expresa una norma superior con base en una norma jerárquicamente inferior.

Por último, también puede resultar problemática la interpretación de la última oración del párrafo -"particularmente si versan sobre el mismo asunto"- porque, o bien expresa algún tipo de preferencia entre textos a utilizar, o bien no expresa absolutamente nada, careciendo la oración de significado normativo. Si se trata del primer caso, entonces cabría interpretar la disposición afirmando que tiene que haber alguna identidad en los casos genéricos o supuestos de hecho regulados en ambos textos. Sin embargo, resulta complicado saber en qué consistiría esta identidad, ya que evidentemente no puede tratarse de normas que regulen el mismo comportamiento, por lo que queda la incógnita de cuándo, según esta interpretación, sería posible acudir a un texto para interpretar otro.

\subsection{6. ¿Exclusión de la interpretación "correctora" por razones ético-políticas?}

La primera oración del artículo 23 afirma que "Lo favorable u odioso de una disposición no se tomará en cuenta para ampliar o restringir su interpretación". Dicha oración puede ser entendida como una regla de segundo orden de exclusión de cualquier interpretación correctora que tienda a modificar la interpretación de una disposición por razón de la injusticia del resultado interpretativo. Pero, pese a su aparente claridad y univocidad, dicha disposición genera varios problemas de interpretación adicionales.

En primer lugar, algunos autores han sostenido que el origen de este artículo se encuentra en que Bello habría querido con este artículo evitar que se siguiera utilizando el Derecho Común frente a su propio texto ${ }^{57}$. Ahora bien, aquel no es un problema de interpretación en sentido estricto sino un problema de fuentes lo que, teniendo en cuenta la práctica desaparición del Derecho Común, conduciría a la conclusión de que este artículo carece de relevancia para la interpretación jurídica hoy en día ${ }^{58}$.

En segundo lugar, dicho enunciado puede ser interpretado como si expresara la norma según la cual el hecho de que una norma atribuya posiciones jurídicas favorables o desfavorables resulta indiferente a la hora de interpretar el alcance de tal norma. Es decir, para establecer su alcance, sería indiferente

57 Véase Bravo (1992).

58 Véase GuZmán (1991), p. 87. 
que la norma conceda derechos subjetivos o imponga obligaciones (ambos en sentido genérico $)^{59}$. Ahora bien, frecuentemente la atribución de una posición favorable a un sujeto, implica que otro sujeto tenga una posición desfavorable, por lo que parece que la tal norma no sería demasiado relevante en muchos casos.

En tercer lugar, hay que determinar si mediante dicho enunciado se está expresando una norma que excluye el argumento apagógico (o reductio ad absurdum), aquel a fortiori y la interpretación analógica (los tres o solo alguno de ellos). A favor de dicha interpretación se podría argüir que, salvo los casos de imposibilidad lógica o empírica, parece que el argumento apagógico implica necesariamente un juicio sobre la justicia o injusticia del caso. Algo parecido sucedería con la interpretación analógica (analogia legis) y a fortiori, que extienden el significado de un enunciado a casos que se considera justo que reciban el mismo tratamiento. Sin embargo, sería posible interpretar tal enunciado de manera tal que no excluya todos estos argumentos.

En cuarto lugar, si consideramos que el enunciado del artículo 23 excluye cualquier tipo de consideración axiológica en la interpretación, ello plantea un problema para la interpretación de todos aquellos términos y expresiones a los que en el lenguaje ordinario se les suele atribuir un sentido ético o moral. Es decir, nos plantea el problema sobre cómo interpretar expresiones como "penas crueles", "buen padre de familia", "dignidad humana" etc. Ello por la sencilla razón de que, según esta interpretación del artículo 23, deberíamos excluir consideraciones valorativas. Si así están las cosas, cabe plantearse si se deben interpretar aquellos términos según la moral social o positiva (y de quién) o si se debe recurrir al significado atribuido a aquellos por la doctrina o la jurisprudencia.

El último problema relativo a esta primera oración del artículo 23 es que afirma que no se podrá modificar la interpretación por razones morales, pero no sabemos cuál es el término comparativo o el tipo de interpretación que no se podría modificar. Se podría suponer que la interpretación que no debe ser objeto de modificación es la literal, pero la plausibilidad de dicha afirmación depende de la solución previa de muchos de los problemas que hemos visto hasta ahora.

\subsection{El genuino sentido de la ley}

La segunda oración del artículo 23 reza de la siguiente forma: "La extensión que deba darse a toda ley, se determinará por su genuino sentido y según las

${ }^{59}$ HOHFELD (1995). 
reglas de interpretación precedentes". Además del ya mencionado problema acerca del significado a atribuir al término "ley" (véase más arriba 3.2), este enunciado nos plantea otros problemas interpretativos.

Ya hemos visto que es posible distinguir entre significado literal y significado obvio, natural o, como se afirma en este caso, genuino. Pues bien, la idea de distinguir entre estos dos tipos de significado se ve reforzada en esta segunda oración del artículo 23. La razón es que al introducir la conjunción copulativa " $y$ ", parece que "genuino sentido" y el resto de "reglas de interpretación precedentes" sean cosas diferentes. Es decir, que el genuino sentido no estaría regulado por las reglas precedentes y sería cosa diferente de aquellas.

Pero, en segundo lugar, esta expresión de la segunda oración puede ser interpretada -"genuino sentido"- también como una nueva remisión al originalismo interpretativo. La expresión "genuino" puede ser entendida en este sentido como sinónima de original, es decir, como referencia al sentido primigenio en el contexto lingüístico de aprobación, y no parece insensato afirmar que dicho significado sería aquel que el autor de la norma otorgó a las palabras que empleó. Por supuesto, este criterio de interpretación genera al menos dos problemas: en primer lugar, establecer en qué sentido usó el legislador las palabras si el contexto lingüístico de aprobación era ambiguo o vago; y, en segundo lugar, cuál es sería la relación de preferencia con el resto de criterios más arriba mencionados.

Por último, también es posible interpretar este enunciado como una mera explicación de lo ya dicho en los artículos precedentes, es decir, como una mera remisión a las normas anteriores sin ulterior distinción o criterio alguno. En este sentido, dicho enunciado no expresaría ninguna norma, o expresaría una norma redundante.

\subsection{El espíritu general de la legislación y la equidad natural}

El artículo 24 -“En los casos a que no pudieren aplicarse las reglas de interpretación precedentes, se interpretarán los pasajes obscuros o contradictorios del modo que más conforme parezca al espíritu general de la legislación y a la equidad natural"- parece, prima facie, introducir una cláusula subsidiaria de cierre. En concreto, la lectura inicial del artículo hace pensar que hay dos criterios -"espíritu general de la legislación" y "equidad natural"- que se aplicarían toda vez que el resto de criterios no pudieran ser aplicados. Esta primera lectura esconde, sin embargo, múltiples problemas.

Si nos fijamos en la condición para la aplicación de estos dos criterios, aquella resulta cuanto menos extraña: la imposibilidad de aplicar las reglas de interpretación precedentes. Dado que no parece imaginable el caso en el que al menos alguno de los criterios pueda -en sentido alético, como posibilidad 
fáctica- ser aplicado, parece necesario buscar una interpretación diferente a la condición ${ }^{60}$.

En este sentido, se podría pensar que la condición de aplicación se refiere a que las normas anteriores generen contradicciones o normas vagas. Ahora bien, si por contradicciones entendemos antinomias -como atribución de calificaciones deónticas incompatibles al mismo comportamiento- los casos de aplicación serían realmente escasos (si es que se daría alguno). Si, en segundo lugar, adoptamos una noción más amplia de contradicciones como atribuciones simultáneas de significados diferentes a un mismo enunciado, entonces estos criterios serían aplicables en todas las ocasiones en las que se produjeran los fenómenos de la ambigüedad o de la vaguedad. Por supuesto, esta circunstancia es contingente pero no por ello poco frecuente.

Nótese que esta interpretación del artículo 24 avalaría la tesis según la cual no existirían meta-reglas de tercer orden que resuelvan las contradicciones en sentido amplio que generan las meta-reglas de segundo orden. En caso contrario, si tales reglas existieran y hubiera una preferencia por la interpretación literal -como muchos parecen suponer- o por cualquier otra, entonces esta primera parte del artículo 24 carecería de razón de ser.

Si vamos al consecuente que bajo esta interpretación expresa esta norma -el uso del espíritu general de la legislación y la equidad natural- entonces debemos preguntarnos si estos dos criterios son el mismo o si, por el contrario, se trata de dos criterios diferentes. Si se trata del primer caso, no quedaría claro en qué consiste dicho criterio.

\subsection{Espíritu general de la legislación}

Aceptando, por hipótesis, que son criterios diferentes, podemos preguntarnos por el significado de cada uno de ellos. Si partimos por el "espíritu general legislación", lo primero que debemos hacer es preguntarnos si se refiere a algo diferente a lo dispuesto en el segundo párrafo del artículo 19: "recurrir a [la] intención o espíritu [de la ley]".

Si se considera que estos dos enunciados introducen criterios interpretativos diferentes, entonces el espíritu general de la legislación no haría referencia a las razones que justificarían una determinada ley, sino las razones que justifican la totalidad de la legislación. Además de que el término "legislación" nos conduce a los mismos problemas que el término "ley", hay que señalar que dicho "espíritu de la legislación" podría ser entendida como la intención del legislador pero también como las razones que impersonalmente justificarían todas las normas.

${ }^{60}$ En cualquier caso, resulta contraintuitivo imaginar un caso que no podamos resolver a través de la interpretación literal, intencionalista, originalista, sistemática, etc. 
Ahora bien, si el espíritu general de la legislación no hace referencia a la intención subjetiva del legislador autor de todas las normas del derecho (lo que constituye una ficción aún más grande que la de la intención del legislador de una sola norma), sino a las razones subyacentes de todo el ordenamiento, las cosas no son precisamente sencillas. Si resulta complicado establecer cuál es "la" razón que justifica la existencia de una norma -habiendo múltiples razones que podrían justificar la misma norma- más difícil aún resulta establecer una justificación de todo el ordenamiento. Ello nos lleva a las grandes reconstrucciones sobre qué es el derecho y cuáles son sus funciones y justificaciones, cuestiones en las que estamos lejos de encontrar un consenso. En síntesis: dado el desacuerdo que tenemos sobre estas cuestiones, cuál sea la interpretación debida según el espíritu general de la legislación conducirá a interpretacionesproducto de lo más diferentes.

\subsection{La equidad natural}

Las cosas no están mejor si nos fijamos en el otro criterio expresado en el artículo 24 del CCCh: la equidad natural. Lo primero que hay que señalar es que no está del todo claro qué quiere decir "equidad natural".

En primer lugar, podría interpretarse que la expresión "equidad natural" es empleada para consagrar la analogia iuris, es decir, aquella técnica mediante la cual se crea una norma nueva, a partir de una norma que califica jurídicamente un caso regulado similar, para calificar un comportamiento no previsto por el ordenamiento.

En segundo lugar, se podría interpretar que dicho artículo viene a autorizar a los aplicadores del derecho a derrotar -esto es, a no aplicar- alguna norma si concurren condiciones axiológicamente relevantes en un caso individual. De este modo, este inciso de este enunciado podría venir a constituir una autorización a los intérpretes para decidir según la justicia del caso concreto, esto es, según la respuesta que se considere más justa para el caso que se está juzgando. Si bien no se trata de un método interpretativo ${ }^{61}$, es sin duda un aspecto relevante para la interpretación entendida en un sentido más amplio (dianoiético) $)^{62}$.

En tercer lugar, el término "equidad" puede ser considerado como sinónimo de igualdad. Como es bien sabido, la igualdad es una propiedad relacional que se predica de al menos dos elementos. No obstante, cuando se habla de

${ }^{61}$ Guastini sostiene la tesis opuesta según la cual la derrotabilidad sería algo similar a la técnica interpretativa de la disociación. Véase GuAstinı (2015), p. 9.

${ }^{62}$ LIFANTE (2015). 
igualdad o de equidad en el ámbito jurídico no es para limitarse a hacer una afirmación de carácter descriptivo sobre cuándo dos entidades se parecen, sino que de lo que estamos hablando es de equidad o igualdad como sinónimos de justicia, entendida esta última como cuándo dos o más sujetos deben ser tratados de la misma manera. Lo que hacemos cuando llevamos a cabo este tipo de juicios es considerar como relevante una determinada característica de un grupo de sujetos a un determinado fin.

La elección de una u otra propiedad como relevante para establecer cómo han de ser tratados un grupo de sujetos a determinados fines es una cuestión práctica, moral o, si se prefiere, ético-política. Pues bien, más allá de que estemos dispuestos a sostener alguna suerte de objetivismo moral en meta-ética, lo cierto es que las sociedades pluralistas modernas como la chilena están recorridas por una serie de desacuerdos morales y ético-políticos. Es decir, la multiplicidad de concepciones del bien y de lo justo conducirán a grandes desacuerdos interpretativos. Si así están las cosas, la remisión a la equidad natural produce otro gran problema interpretativo.

Por último, hay que señalar que, aunque se trata de una norma subsidiaria de cierre, esta norma interpretativa estaría en contradicción al menos con alguna de las interpretaciones posibles del artículo 23, el cual-como vimos- introduce una norma interpretativa de segundo orden que excluye la posibilidad de modificar una interpretación por razones prácticas, morales o ético-políticas.

\subsection{Interpretación sistemática: ¿orden lexicográfico?}

Para finalizar, voy a analizar tres problemas que, en sentido estricto, no surgen de la atribución de significado a los enunciados de los artículos 19 a 24 del CCCh, sino que más bien corresponden a construcciones dogmáticas.

El primero de ellos es la posibilidad de considerar que existe una preferencia de las diferentes normas primarias y secundarias de interpretación según el orden de aparición de aquellas. Esto, ciertamente, solucionaría buena parte -aunque no todos- los problemas de interpretación que se han señalado, especialmente en lo relativo a las reglas de preferencia y exclusión de segundo orden. Sin embargo, el problema de esta tesis es que no cuenta con demasiadas bases textuales, aunque tampoco las había para establecer, como se ha defendido, un orden lexicográfico entre los derecho establecidos en el artículo 19 de la CPR ${ }^{63}$.

${ }^{63}$ Cea (2003), p. 66. 


\subsection{La exhaustividad de los criterios de interpretación}

El segundo problema se refiere a si las normas interpretativas de los artículos 19 a 24 constituyen una lista cerrada -siendo los únicos criterios interpretativos que se pueden utilizar- o si, por el contrario, se trata de una lista abierta. La pregunta resulta relevante en la medida en que, por muy extensiva que sea la interpretación que realicemos de estos artículos, lo cierto es que no resulta posible incluir todos los criterios interpretativos que usan los juristas entre los contemplados en los mencionados artículos. Bastan un par de ejemplos para dar cuenta del problema: ¿está permitida la interpretación con base a las consecuencias de la norma derivada del enunciado normativo? ¿Es posible la interpretación a contrario? No parece que haya bases textuales suficientes para responder positiva o negativamente a estos últimos interrogantes.

\subsection{Interpretación legal e interpretación constitucional}

El último problema de interpretación hace referencia a la relación entre interpretación constitucional y la interpretación de la ley. Es decir, no tanto a sobre si estos criterios de interpretación son aplicables a la interpretación constitucional (cuestión que también podría ser objeto de controversia), cuanto al problema del papel que queda reservado a aquellos frente al problema de la interpretación conforme. Parece pacífico sostener que la interpretación de los textos infraconstitucionales tiene que no entrar en conflicto con él significados atribuidos a los enunciados constitucionales.

Ahora bien, la interpretación conforme a la constitución tiene dos aspectos: uno negativo (o débil) y uno positivo (o fuerte) ${ }^{64}$. En su aspecto negativo, la interpretación conforme funciona como una meta-regla de exclusión negativa que permite eliminar significados atribuidos a textos de menor rango jerárquico cuando aquellos supongan una contradicción con una norma de mayor rango jerárquico. En su aspecto positivo, la interpretación conforme implica que se debe atribuir a los textos infraconstitucionales aquella interpretación "más" conforme a la propia constitución.

Más allá de que resulta complicado establecer cuándo una norma es "más" conforme que otra a la Constitución, lo cierto es que adoptar una versión fuerte o positiva de la interpretación conforme a la constitución hace completamente irrelevantes los criterios de interpretación del CCCh. Por supuesto, cuál de las versiones de la interpretación conforme haya que seleccionar es cuestión controvertida.

${ }^{64}$ Soy deudor en este punto de un trabajo aún no publicado, y de una discusión respecto de aquél, de Jose Ángel Fernández Cruz. 


\section{Algunas conclusiones provisionales}

De lo dicho hasta ahora podemos llegar a algunas conclusiones.

4.1. La primera conclusión es que existen dudas tanto acerca de cuáles son los criterios de interpretación positivizados en los artículos 19 a 24 del CCCh, así como sobre las normas de interpretación de segundo orden. Es más, ni siquiera es posible decir que sean únicamente aquellos mencionados en el CCCh los únicos instrumentos interpretativos que se pueden usar para interpretar la ley o el derecho chilenos.

Si tenemos dudas tanto acerca de cuáles son los criterios interpretativos de primer y segundo orden, como también de las relaciones entre tales criterios, entonces parece que los intérpretes podrán, justificadamente, atribuir significados discordantes a un mismo enunciado normativo. Ello debido a que los artículos 19 a 24 del CCCh podrían establecer, según interpretaciones plausibles de aquellos, varios criterios de interpretación para el resto del ordenamiento. Por tanto, qué normas sean las expresadas por el resto de los enunciados jurídicos del derecho chileno dependerá, en última instancia, de las preferencias del intérprete por unos criterios interpretativos u otros (o por las diferentes interpretaciones producto posibles) dentro de aquellos criterios que pueden desprenderse de los artículos 19 a 24 del CCCh.

4.2. Sin embargo, la conclusión anterior no implica que no haya interpretaciones válidas ni interpretaciones inválidas; tampoco se sigue que es posible, de conformidad con los artículos 19 a 24 del CCCh, cualquier interpretación de los textos normativos, sino un conjunto amplio de interpretaciones pero no infinitas. Implica, de este modo, que frecuentemente habrá más de una interpretación válida de las leyes chilenas -producto del uso de los diferentes técnicas y criterios interpretativos-, y que el intérprete no tiene criterios jurídicos definitivos y unívocos para elegir entre ellas.

4.3. La tercera conclusión es la carencia de justificación de cualquier tesis que pretenda ofrecer en términos descriptivos un meta-criterio interpretativo de segundo orden absoluto (o una ordenación no vaga ni antinómica de diferentes criterios interpretativos), como la opción jurídicamente debida, como la única opción derivable de los enunciados normativos del derecho (y, para quien considere que es debido obedecer el derecho, como la opción obligatoria). Para que dichas tesis estuvieran suficientemente justificadas, sería necesario que aquellas probaran la existencia de una meta-meta-norma de tercer orden capaz de dirimir los conflictos entre las normas de primer y/o segundo orden.

Como anuncié al principio, dichas doctrinas pueden ser entendidas como tesis descriptivas o como tesis de filosofía política normativa acerca de qué debería decir el derecho. El problema es que cuanto tesis descriptivas parecen 
ser falsas o, al menos, están insuficientemente justificadas (en el sentido de que disponemos de otras interpretaciones igualmente justificadas, y carecemos de meta-criterios de origen jurídico para decidir entre aquellas); y en cuanto tesis de política normativa, requerirían una mayor fundamentación -no en términos jurídicos-, sino precisamente ético-políticos, extra-jurídicos.

4.4. La cuarta y última conclusión es que se puede dudar de que tenga sentido seguir discutiendo en términos descriptivos sobre cuál es la interpretación verdadera de los artículos 19 a 24 del CCCh. Si lo que se quiere es orientar la actividad interpretativa de quienes aplican el derecho, parecería más sensato comenzar una discusión normativa extra-jurídica, basada en consideraciones sobre cómo queremos que interpreten y decidan los aplicadores del derecho. Tratar de seguir apoyando tales doctrinas de la interpretación en argumentos de carácter teórico o descriptivo (o histórico) conduce exclusivamente a intentar responder a preguntas normativas con base en argumentos descriptivos.

\section{BIBLIOGRAFÍA CITADA}

Alfonso, Paulino (1892): De la interpretación de la ley (Santiago, Imprenta Cervantes).

Arena, Federico (2014): El convencionalismo jurídico (Madrid, Marcial Pons).

Bascuñán Rodríguez, Antonio (2013) "El mito de Domat", en: Atria, Fernando et al. (eds.), Una vida en la Universidad de Chile: celebrando al Profesor Antonio Bascuñán Valdés. (Santiago, Legal Publishing), pp. 1-63.

Bravo LiRa, Bernardino (1992): "Odia restringi", en: Simon, Dieter y Stolleis, Michael (eds.), lus Commune (Frankfurt, Klosterman), pp. 81-93.

Bulygin, Eugenio (1992): "Sull'interpretazione giuridica", en: Analisi e diritto, pp. 11-30.

Cea Egaña, Jose Luis (2003): Derecho constitucional chileno (Santiago, Universidad Católica de Chile), tomo II.

Claro Solar, Luis (1898): Explicaciones de Derecho Civil Chileno y Comparado (Santiago, Establecimiento Poligráfico Roma).

ChIASSONI, Pierluigi (2011): Técnicas de interpretación jurídica (Madrid, Marcial Pons).

Dıcıotтı, Enrico (1999): Verità e certezza nell'interpretazione della legge (Torino, Giappichelli).

DucCl Claro, Carlo (1977): Interpretación Jurídica (Santiago, Editorial Jurídica de Chile). 
Hohfeld, Wesley Newcomb (1995): Conceptos jurídicos fundamentales (México, Fontamara).

GuASTINI, Riccardo (2004): L'interpretazione dei documenti normativi (Milano, Giuffrè).

—_ (2011): Interpretare e argomentare (Milano, Giuffrè).

— (2015): “Interpretación y construcción jurídica”, en: Isonomía, 18 páginas (en prensa).

GuZMÁN BRITO, Alejandro (1992): “La historia dogmática de las normas sobre interpretación recibidas por el Código Civil de Chile", en: AA.VV., Interpretación, integración y razonamiento jurídicos (Santiago, Editorial Jurídica de Chile), pp. 41-87.

— (2007): La reglas del Código Civil de Chile sobre interpretación de las leyes (Santiago de Chile, LexisNexis).

ITURRALDE, Victoria (2014): Interpretación literal y significado convencional (Madrid, Marcial Pons).

Kristan, Andrej y Pravato, Giulia (2016): "Faultless Disagreement in Matters of Law" (en prensa).

KelSeN, Hans (2011): "Sobre la interpretación", en: Eunomía, pp. 173-184.

LAPORTA, Francisco (2007): El imperio de la ley (Madrid, Trotta).

LIFANTE, Isabel (1999): "Interpretación y modelos de derecho. Sobre el papel de la intención en la interpretación jurídica", en: Doxa (№ 22), pp. 171-193.

(2015): "Interpretación jurídica", en: Fabra, Jorge y Rodríguez Blanco, Verónica (eds.), Enciclopedia de Filosofía y Teoría del Derecho (vol. II) (México, UNAM), pp. 1349-1387.

Marmor, Andrei (1995): "Autoridades y personas", en: Doxa (No 17-18), pp. 303-330.

MAZZAReSE, Tecla (1998): "La interpretación como traducción", en: Isonomía (No 9), pp. 73-102.

OliveCRONA, Karl (1980): El derecho como hecho. La estructura del ordenamiento jurídico, $2^{\mathrm{a}}$ edición (Barcelona, Labor).

Pozzolo, Susanna (ed.) (2011): Disposición Vs. Norma (Lima, Palestra).

NúÑez Vaquero, Álvaro (2014a): "Kelsen en la encrucijada", en: lus et praxis (año 20, № 2), pp. 415-442.

— (2014b): "Ciencia jurídica: un mapa conceptual", en: NúÑez Vaquero et al. Modelando la ciencia jurídica (Lima, Palestra), pp. 13-51.

— (2014c): "Dogmática jurídica", en: Eunomía (№ 6), pp. 245-260. 
RAZ, Joseph (1997): "La intención en la interpretación", en: Doxa (№ 20), pp. $199-233$

Rodíguez Grez, Pablo (1990): Teoría de la interpretación jurídica (Santiago, Edición privada).

TARello, Giovanni (2013): La interpretación de la ley (Lima, Palestra).

NORMAS JURÍDICAS CITADAS

Código Civil de Chile.

Constitución Política de la República de Chile. 